\title{
Patient Satisfaction Studies and the Monitoring of the Right to Health: Some Thoughts Based on a Review of the Literature
}

\author{
Emmanuel Kabengele Mpinga (Corresponding author) \\ Institute of Social and Preventive Medicine \\ Faculty of Medicine, Geneva University \\ CMU - Michel Servet, 1, 1211 Geneva 4, Switzerland
}

Tel: 41-22-379-0463 E-mail: Emmanuel.Kabengele@unige.ch

\author{
Philippe Chastonay \\ Institute of Social and Preventive Medicine \\ Faculty of Medicine, Geneva University \\ CMU - Michel Servet, 1, 1211 Geneva 4, Switzerland \\ Tel: 41-22-379-0462 E-mail: Philippe.Chastonay@unige.ch
}

Received: October 21, 2010 Accepted: November 5, 2010 doi:10.5539/gjhs.v3n1p64

\begin{abstract}
The concept of patient satisfaction has a long history of controversy and debate. Yet it remains a topic of scientific investigation. Little is known about its importance as a tool for monitoring the right to health. A non-exhaustive review of scientific articles reported in Medline was done in order to better understand how patient satisfaction can be investigated and what it indicates.

Over time and years the concept of patient satisfaction shows an evolution towards complexity, while becoming more operational. Indeed patient satisfaction studies have proved of value as a health indicator and allowed the implementation of improvement strategies in the health sector based on "the voice of the patient", thus becoming a potential right to health indicator. However they do have limits, but we consider nevertheless that they are of interest as a health indicator and that they should be put as such on the public health agenda.
\end{abstract}

Keywords: Patient satisfaction, Right to health, Monitoring, Indicator

\section{Patient Satisfaction: What Does It Indicate?}

\subsection{The concept of patient satisfaction}

The concept of patient satisfaction has a long history of controversy and debate. Yet patient satisfaction remains a topic of scientific investigation. But little is known about its relations and importance regarding the monitoring of the right to health.

Indeed, ever since in the fifties patient satisfaction became a topic in health care settings (Abdellah and Levine, 1957), there has been a growing scientific interest. Medline reports from 1968 to 1977 less than one hundred publications on patient satisfaction, whereas there are nearly 4000 publications between 1998 and 2007 (Medline accessed on February 26th 2009). Early on many articles were centered on the development and utilization of specific tools (Risser, 1975; Ware et al. 1977; Mac Keigan and Larson, 1989; Wilson et al. 2006).

Over time more focus was put on the clarification of the concept of patient satisfaction (Williams, 1994; Wagner and Bear, 2009), on the identification of essential components of patient satisfaction (Perreault et al. 2001; Hall and Dornan, 1988) and on its specific explanatory factors (Huang et al. 2004; Bautista et al. 2007). Furthermore studies explored the relationship between patient satisfaction and the quality of care (Van Campen and Sixma, 1995, Hutchison et al, 2003) as well as its evolution over time, in different groups of patients and in various health care settings and cultural or geographical contexts (Allan et al. 2009; McCabe et al. 2008; Piron et al. 2008; Kikwilu et al. 2009; Lochoro, 2004). 
From Risser in 1975 to Mrayyan in 2006 (Mrayyan, 2006), and with the input of Lochoro in 2004 and Wolosin in 2005 (Wolosin, 2005), the concept of patient satisfaction has moved from a more theoretical essence to a more technical and operational approach.

Risser considers patient satisfaction as the degree of convergence between the expectations the patients have of ideal care and their perception of the care they really get (Risser, 1975).

Lochoro supports this point of view: he notes that patient satisfaction corresponds to the gap between the expected and perceived characteristics of a service (Lochoro, 2004).

These considerations are based on Donabedian's work who defines patient satisfaction as the expression of patient's judgment on the quality of care received in all aspects, but particularly as concerns the interpersonal process' (Donabedian, 1988).

Wolosin (Wolosin, 2005) considers that patient satisfaction as an indicator of the quality of care and integrates in its definition the patients' experiences as a key-element of (un)satisfaction. He argues that experiences that exceed expectations lead to satisfied patients, while those that fail to meet expectations cause dissatisfaction. Patient's satisfaction is the voice of patient that counts since it reflects the response to experienced interactions with the care givers.

Marayyan (Mrayyan, 2006) enriches the concept with new dimensions. Patient satisfaction becomes the degree to which nursing care (as well as public health activities) meets patients' expectations in terms of art of care, technical quality, physical environment, availability and continuity of care and the efficacy loutcomes of care.

\section{The components of patient satisfaction}

The components of patient satisfaction can be summarized as "the quality and accessibility of medical care, availability of health services and structures, affordability of costs, information and participation of the patient". More specifically key constituents of patient satisfaction are (Risser, 1975; Ware et al, 1977; Hall and Dornan, 1988; Lochoro, 2004, Baker, 1991, Mahon, 1996):

The quality of medical care, which includes competent health professional, adequate infrastructure and health services, appropriate diagnostic and therapeutic procedures,

Adequate information on disease and therapy,

Equity in the accessibility to diagnostic, therapeutic and preventive measures,

Reasonable costs and affordable health insurance system for the individual and the community,

Acceptable "waiting time" and appropriate "hostelry",

Participative approach of care and prevention (integration of the patient and his family in the decision procedures).

\section{Patient Satisfation: How To Measure It?}

\subsection{The patient satisfaction studies}

Measuring patient satisfaction is not an easy task. It requires a) a clear definition of the objectives; b) the identification of the target populations; c) well defined tools and ways to collect the data; d) a strategy for analyzing the data and its utilization. It can focus on the process and/or the results of care. It also allows patients to evaluate received services and treatments. Finally measuring patient satisfaction allows the identification of possible problems and suggests ways of improving the quality of care or public health interventions (Druss, 1999; Harris et al. 1999).

Patient satisfaction measuring tools are numerous and vary accordingly to the field to be investigated. For example, in the field of cancer a review of the literature on 1803 studies reported 36 different tools to measure patient satisfaction. In the field of diabetes between 1987 and 1997 eight different tools have been developed and used (Diabetes attitude Scale, Diabetes Treatment Satisfaction Questionnaire, Treatment Satisfaction and Psychological Well-being, The Ipswich Diabetes Self - Management Questionnaire, Diabetes Care Profile, Diabetes Quality of Life et Picker Patient Satisfaction Survey). Such a proliferation of tools implies that for a given research question the appropriate tool is chosen, a tool that furthermore has proven its validity, fiability, acceptability and feasibility (Richardson et al. 2007; Paddock et al, 2000; Panvelkar, 2009).

Throughout the world patient satisfaction studies are widely used to evaluate the quality of care as well as public health programs' acceptability and impact. They have been implemented in various cultural contexts and in different health systems as well as among patients suffering from specific pathologies (Wilson et al. 2006; 
Perreault \&al 2001; Huang et al. 2004; Bautista et al. 2007; Hutchison et al. 2003; Allan et al. 2009; Piron et al. 2008; Mrayyan, 2006; Wolosin, 2005).

Over the past thirty years patient satisfaction might well be one of the most studied topics in health sciences, if one considers the amount of published articles, the diversity of analytic approaches, the extent of the debate. To be mentioned also is the variety of tools developed in order to measure patient satisfaction, of which many have been validated allowing international comparison and long-term follow-up (Mahon, 1996; Defossez et al. 2007; Hendricks et al. 2002).

The measurement of patient satisfaction is of value to the health system: indeed, it allows a) to describe and characterize its functioning; b) to identify existing problems in the sector; c) to evaluate the quality of care (Stizia and Wood, 1997).

Some authors report that patient satisfaction studies have a real impact on the attitudes and behaviors of health professionals and are prone to induce improvement measures in the health services (Greco et al. 2001). A French study for example reports that among health care professionals of an university hospital $94 \%$ have a good opinion of patient satisfaction studies, $60 \%$ are aware of the results of such studies done in their department and $40 \%$ report that those studies have brought improvements to the services and modified their own behavior (Boyer et al. 2006).

\subsection{Limits of the patient satisfaction concept and related studies}

Two recent reviews analyze the major critiques of the patient satisfaction concept and related studies:

The first one is a review of the literature by Hekkert (Hekkert et al. 2009). The authors report the critiques and observations done by Avis and Bond 1997, Fizpatrick and Hopkins 1983; Jenkinson, Coulter et al. 2002; Pascoe 1983; Sixma, Kerssens et al. 1998; Williams 1994; Stizia 1997; Merkouris, Papathanassoglu et al. 2004;

The second is a review by Gill and White (Gill and White, 2009) based mainly on the studies of Heidegger et al.2006; Sofaer and Firminger 2005, Hawthorne 2006; Gonzales et al. 2005; and Gilbert and Veloutsou 2006.

The major critiques mentioned in these reviews are the lack of consensus on the concept of patient satisfaction, its subjectivity, the weak discriminative power of the measuring tools, the lack of validity per se of those tools and the strong focus on clinical settings of the studies.

The lack of consensus around the concept of patient satisfaction has "historical reasons" due to the fact that a large number of studies on patient satisfaction were done prior to the clarification of the concept and were determined by the mono-disciplinary of many researchers approach, be it nurses, physicians, psychologists, managers, etc. At present a consensus seems at last to emerge however (Leplege and Coste, 2002).

The subjectivity of patient satisfaction studies is primary due to the fact that they measure the personal perception, values and attitudes of patients. Though considered as a weak point by many researchers, the subjectivity is considered by some as a strong point, since it integrates the psychological dimension of the evaluation of care by the patients (Ware et al, 1977, Hekkert et al, 2009).

The weak discriminative power of patient satisfaction studies relates to the high satisfaction scores commonly reported $(75-90 \%)$. However this might well be related to the patient per se than to the methods of collecting the information (tools of collecting data, scale of measuring, ways of submitting the questionnaires to patients, etc) as suggested by some authors (Ware et al. 1977; Ross et al. 1995). This underlines the importance of validating data collecting tools.

The strong focus on clinical settings of patient satisfaction studies is quite real, yet it has been diminishing over the years (Wolosin, 2005).

Two strong points of patient satisfaction studies are of technical dimension: their high participation rate and their statistical power.

High participation rates have been reported in several reviews: Stizia and Wood (39) having reviewed 219 articles from 141 different scientific journals report a mean participation rate of 72.1\%; Asch et al. (40) having reviewed 178 studies published in medical journals report a participation rate of $60 \%$. High statistical power relates to the thousands of patients interrogated in those studies.

\section{Patient Satisfaction and the Right to Health}

When considering the respect and protection of the health of populations, the obligations of states are determined by national and international laws as well as human rights conventions and treaties. The General Observation 14 of the Committee for economic, social and cultural rights of the UN Economic and Social Council, commenting 
on the right to health, reaffirms the essential components of the right to health as state obligations. These components are:

The availability of health services, health infrastructure and public health programs,

The non-discriminatory (physical, economic, information) access for all to health care and prevention programs,

The acceptability (ethical, gender-related, cultural) of health services and programs,

The quality of care, i.e. health procedures and programs must be scientifically and medically sound which in turn implies competent health professionals, adequate medication and appropriate infrastructure (ECOSOC, 2000).

Those right to health constituents are in perfect correspondence with patient satisfaction components as described in the literature and presented above (paragraph 1.2): this suggests in our view that patient satisfaction could serve as a potential indicator of the right to health, allowing to monitor to what extent the right to health has been integrated in a given health structure specifically or in the health sector more broadly.

Beyond these technical aspects patient satisfaction studies present in our view some other strong points regarding the monitoring of the right to health.

First, it suits a democratic society to take into account the opinion of patients in any health policy decision; i.e promoting a participative process in the evaluation of health care activities seems to be a central value of modern societies. This is reported to restore confidence into public services, to improve the quality of care and to strengthen social links in the community. It also seems to promote a pluralistic model of decision-making (Taylor, 2009).

Second, in parallel to the socio-economic and technological evolution in recent decades there has been an evolution of the patient-health professional relationship. The consequence has been new expectations and demands regarding health care practice: i.e. health care practice centered on the patient, which in turn pledges for a patient-health professional relationship based on partnership rather than paternalism (Mead and Bower, 2000; Taylor, 2009).

Third, in many countries patient satisfaction studies have become an important indicator of the quality of care, in some they are even legal obligations. In France patient satisfaction studies have been labeled as "priority" since 1996 (Revilla et al. 2008) and Great-Britain has identified patient satisfaction as one of its reform priorities as early as the 1980 (Stizia and Wood, 1997).

Fourth, the health system of the future should be patient-centered, with the patient as a key-evaluator (IOM2001).

Finally, patient satisfaction, in promoting partnership among various actors of the health system (patients, health professionals, managers, politician), contributes to the protection and the promotion of the right to health care. As an example one might mention the "Core questionnaire for patient satisfaction project" in the Netherlands done in close collaboration by the Dutch Inspectorate for Health and the national Hospital Association: patient satisfaction surveys done throughout the country's hospitals are published annually on the Internet (Hekkert et al. 2009).

\section{Conclusion}

In our view the literature suggests that patient satisfaction studies, be it in their founding concepts or in their more technical aspects, have a potential political, social and ethic impact, which strengthens their usefulness as a monitoring tool of the right to health.

Patient satisfaction builds on ethical, deontological and moral foundations. The principles of autonomy (free choice, participation, etc.), beneficence and non maleficence (scientific soundness, technical competency, capacity to empathy, etc.) should be respected by health professionals and be an integral part of the mechanisms of implementation and surveillance quality of care and basic rights of patients.

Perhaps patient satisfaction could be considered in the future as a right to health indicator making its contribution in monitoring the progress states have achieved in regard to implementing the right to health for the populations they are in charge of. Indeed patient satisfaction studies do yield valuable information on accessibility / inaccessibility to quality health care as well as on true/fake patient participation, adequate/inadequate circulation of information and appropriate/ inappropriate allocation of resources, ultimately being of interest to health policy decision makers. 


\section{References}

Abdellah FG, Levine E. (1957). Developing a measure of patient and personnel satisfaction with nursing care. Nursing research, 5:100-108

Allan J, Schatter P et al. (2009). Does patient satisfaction of general practice change over a decade? BMC Fam Pract, Feb 8; 10:13

Asch DA, Jedrziewski MK et al. (1997). Response rates to mail surveys published in medical journals. $J$ Clin Epidemiol, 50(10):1129-36.

Baker R. (1991). The reliability and criterion validity of a measure of patients' satisfaction with their general practice. Fam Practice, 8:171-177.

Bautista RE, Glen ET et al. (2007). Factors associated with satisfaction with care among patients with epilepsy. Epilepsy Behav, 11(4):518-524.

Boyer L, Francois P et al. (2006). Perception and use of the results of patient satisfaction surveys by care providers in a French teaching hospital. International Journal of quality in health care, 18(5): 359-364.

Conseil Economique et Social des Nations Unies. (2000). Le droit au meilleur état de santé susceptible d'être atteint. Observation générale $14 \mathrm{du}$ Comité des droits économiques sociaux et culturels. E/C.12/2000/4 du 11 août 2000. [Online] Available: http://daccess-dsny.un.org/doc/UNDOC/GEN/G00/439/35/PDF/G00439 35.pdf?OpenElement

Defossez G, Mathoulin-Pelissier S et al. (2007). Satisfaction with care among patients wit no-metastatic cancer: development and First step of validation of the REPERES-60 questionnaire. BMC Cancer, 7:19.

Donabedian A. (1988). The quality of care: how it can be assessed? Journal of American Medical Association, 260(12): 1743-1748.

Druss GB. (1999). Patient satisfaction and administrative measures as indicators of the quality of mental health acre. Psychiatric Services, 50 (80): 1053- 1058.

Gill L, White L. (2009). A critical review of patient satisfaction. Leadership in Health Services, 22(1): 8-19.

Greco M, Brownlea A et al. (2001). Impact of patient feed back on the interpersonal skills of general practice registrars. Results of a longitudinal study. Med Educ, 35:748-56.

Hall JA, Dornan MC. (1988) What patients like about their medical care and how often they asked: a meta analysis of the satisfaction literature. Soc Sci Med,27:935-9.

Harris EL, Swindle WR et al. (1999). Measuring patient satisfaction for quality improvement. Medical Care, 37(12):1207-1213

Hekkert KD, Cihangri S et al. (2009).Patient satisfaction revisited: a multilevel approach. Soc Sci Med, 68-75.

Hendriks AAJ, Oort FJ et al. (2002). Reliability and validity of the satisfaction with hospital care questionnaire. International Journal of quality in health care, 14:471-482.

Huang JA, Lai CS et al. (2004). Determining factors of patient satisfaction for frequent users emergency services in a medical center. J Chin Med Assoc, 67(8):403-10.

Hutchison B, Ostbye T et al. (2003). Patient satisfaction and quality of care in Walk-in clinics, family practices and emergency departments: the Ontario Walk-in Clinic Study. CMAJ, 169(1):977-83.

IOM- Committee on quality of care in America. (2001). Crossing the Quality Chasm: a new health system for the 21st century. National Academy Press. Washington 2001, 360p.

Kikwilu EN, Kahabuka FK et al. (2009). Satisfaction with urgent oral care among adult Tanzanians. J Oral Sci, 51(1):47-54.

Leplege A, Coste J. (2002). (sous la direction de) Mesure de la santé perceptuelle et de la qualité de vie: méthodes et application, Estem eds, Paris 2002, 333p.

Lochoro P. (2004). Measuring patient satisfaction in UCMB Health Institutions. Health and Policy Development, 2(3):243-248.

Mac Keigan LD, Larson LN. (1989). Development and validation of an instrument to measure patient satisfaction with pharmacy services. Med Care, 27(5):522-36. 
Mahon YP. (1996). An analysis of the concept » patient satisfaction » as it relates to contemporary nursing care. Journal of Advanced Nursing, 24:1241-1248.

McCabe MP, Roberts C et al. (2008). Satisfaction with services among people with progressive neurogical illnesses and their carers in Australia. Nurs Health Sci, 10(3):209-15.

Mead N \& Bower P. (2000). Patient centredness: a conceptual framework and review of the empirical literature. Soc Sci Med, 51:1087-1011.

Mrayyan MT. (2006). Jordanian nurses' job satisfaction, patients' satisfaction and quality of nursing care. International Nursing Review, 53:224-230.

Paddock EL, Veloski J, Geviritz OF et al. (2000). Development and validation of a questionnaire to evaluate patient satisfaction with diabetes disease management. Diabetes Care, 23: 951-956.

Panvelkar NP, Saini B, Armour C. (2009). Measurement of patient satisfaction with community pharmacy services: a review. Pharm World Sci, 31:525-537.

Perreault M, Katerelos TE et al. (2001). Information as a distinct dimension for satisfaction assessment of outpatient psychiatric services. Int J Care Qual Assur Inc Leadersh Health Serv, 14(2-3):111-20.

Piron L, Turolla A et al. (2008). Satisfaction with care in post-stroke patients undergoing a telerehabilitation programme at home. $J$ Telemed Telecare, 14(5):257-60.

Revilla A, Taboulet $\mathrm{P}$ et al. (2008). La satisfaction des patients aux urgences est-elle comparable à celle des soignants? Urgence Pratique, 90:5-8.

Richardson A, Medina J, Brown V et al. (2007). Patients' needs assessment in cancer care: a review of assessment tools. Support care cancer, 15(10):1125-44.

Risser NL. (1975). Development of an instrument to measure patient satisfaction with nurses and nursing care in primary care settings. Nursing research, 24(1):45-52.

Ross CK, Steward CA et al. (1995). A comparative study of seven measure of patient satisfaction. Med Care, 33(4): 392-406.

Stizia J, Wood N. (1997). Patient satisfaction: A review of issues and concepts. Soc Sci Med, 45(12): 1829-1843.

Stizia J, Wood N. (1998). Response rate in patient satisfaction research: an analysis of 219 published papers. International Journal of quality in health care,10(4):311-7.

Taylor K. (2009). Paternalism, participation and partnership-the evolution of patient centerdness in the consultation. Patient Educ Couns, 74:150-155.

Van Campen C, Sixma H. (1995). Quality of care and patient satisfaction: a review of measuring instruments. Med Care Res Rev, 52(1):109-33.

Wagner D, Bear M. (2009). Patient satisfaction with nursing care: a concept analysis within a nursing framework. $J$ Adv Nurs, 65(3):692-701.

Ware JE Jr, Davies Avery A et al. (1977). The measurement and meaning of patient satisfaction: A review of the literature. Rand Papers Series. Santa Monica, California, 1977, 39p.

Ware JE, Synder MK et al. (1977). Some issues in the measurement of patient satisfaction with health care. Rand Papers Series. Santa Monica, California, 1977.

Williams B. (1994). Patient satisfaction: a valid concept. Soc Sci Med, 38(4):509-16.

Wilson A, Hewitt G et al. (2006). Development and testing of a questionnaire to measure patient satisfaction with intermediate care. Qual Saf Health Care, 15(5):314-9.

Wolosin RJ. (2005). The Voice of the patient: A national representative study of satisfaction with family physicians. Q Manage Health Care, 14(3):155-164. 